\title{
The gathering clouds of grey on the horizon - the healthcare challenges of our aging population
}

\author{
Arvind Kasthuri \\ Professor, Department of Community Health \& Coordinator, Senior Citizen Health Service, St John's Medical College, \\ Bangalore, India \\ Correspondence: arvindk@gmail.com
}

DOI: https://doi.org/10.4038/jccpsl.v25i1.8201

Received on: 19 January 2019

Accepted on: 25 March 2019

The spectacular rise of the elderly population globally has spurred interest in the phenomenon of aging and its ramifications in terms of the characteristics and needs of elderly people. Biologically, 'aging' is defined as a progressive functional decline or a gradual deterioration of physiological function with age (1). Socially, the characteristics of members of society perceived as being 'old' vary with the cultural setting and from generation to generation. Economically, especially in rural areas, 'old people' are simply seen as being those who are too old to work and earn. Chronologically, numeric age has been traditionally used in defining the term 'elderly'. Even though a single 'cut-off' age which would define the elderly would vary between country and region considering the biologic, sociologic and economic differences in their populations, the United Nations in 1980 defined 60 years as the age of transition of people to the elderly segment of the population (2). Some authors classify the elderly as the young old (60-70 years), the old old (70-80 years), the oldest old ( $80+$ years), the centenarians (100 years + ) and super-centenarians (110 years+) (3).

\section{Population trends: globally and in the WHO South East Asian region (SEAR)}

The population of elders aged 60 years and above, which was 142 million in SEAR in 2010 is likely to increase steeply by 100 million in the next 15 years to cross the 242 million mark by 2025 . The world as a whole will have about 435 million additional elderly persons and the number of elderly persons as a whole is projected to reach 1.2 billion by 2025 from the 765 million elderly persons in 2010 (4). In fact, by the year 2050, projections indicate that there will be more persons aged 60 years or over in the world than adolescents and youth at ages $10-24$ years (2.1 billion versus 2.0 billion) (5).

The proportion of population aged 60 years and above in the SEAR is seen to be rising at a rapid rate. It was $8.9 \%$ in 2012 and is expected to be $23 \%$ by 2050 (6). This translates into almost a quarter of the population of the region being elderly, which is a huge demographic challenge for any of the SEAR countries.

The determinants of this rise in the proportion of elderly include fertility, mortality and life expectancy, as measured by the total fertility rate (a measure of the number of children a woman will bear during her lifetime), crude death rate and the expectation of life at birth.

The total fertility rate for the world as a whole was around 5.06 in 1964, and has since reduced to 3.66 in 1981, 3.16 in 1991 and to 2.44 in 2016 (7). In the SEAR, the total fertility rate has in general reduced from levels of 4-6 to 2-2.5 between 1985 and 2014. This implies that the proportion of young persons will reduce in the years to come, as the "bulge" in the agesex pyramid moves upward from the base, leading to 
a higher proportion of people in the older age groups. The median age is defined as the age that divides the population into two equal halves. In the 50 years between 1950 and 2000, the median age of the world's population increased by just three years, from 23.6 in 1950 to 26.4 in 2000 . It is currently estimated to be 30.6 years, testimony to the accelerated growth of the elderly population and the reduction in the younger age groups "joining" the global population (8). The median age in SEAR was estimated to be 27 years in 2013.

The crude death rate globally had almost dropped by half from 17.7 per 1000 persons in 1960 to 9.2 per 1000 persons in 1990 . It is currently estimated at about 7.6 per 1000 . In the same period, the expectation of life at birth globally was 52.5 years in 1960, had risen to 65.4 years in 1990 and is expected to be around 72 years currently (9). The expectation of life at 60 years in the SEAR was 16.7 years, which has risen to over 18.2 years now $(10)$.

\section{Healthcare challenges faced by the elderly population}

The high and growing number of persons above the age of 60 years poses challenges to society globally, regionally and locally. While there are differences in the economic levels among countries of the SEAR, the problems faced by the elderly appear similar. These include the huge problem of adequate care and support, stemming from the lack of an organised social security system as exist in many western societies. Added to this is the changing social fabric especially in congested urban areas, where migration and change in value systems lead to isolation and loneliness in old age. Economic insecurity can lead to a renewed poverty at the time it hurts most - old age.

Groups have been identified within the elderly segment as those likely to face particular risk with respect to their health status. Such 'high-risk' elderly includes (11):

- The oldest old, more than 80 years old

- Elderly living alone and couples living by themselves

- Elderly women, especially single and widowed

- An elderly couple where one member is ill

- Elderly living in institutions as opposed to those living with families
In a recent paper, I have suggested that the challenges facing healthcare in India could be considered under the 'Five As' (12). While the issues concerning the elderly are many and diverse, our experience with working with older persons in rural and urban areas in a crowded metropolis in India suggests that the same framework (the five, as outlined below) may be applied when considering the healthcare challenges facing the elderly:

\section{Access, or lack of it}

Health care services, even if deemed available as provided by the state in some countries of the SEAR are not equally accessible to all people of the region. The reasons for poor access could vary from problems of geography and distant facilities, to issues with the social determinants of access such as literacy and socio-economic status and to problems of lack of availability of services that the older population needs at state-run facilities (13). At a micro-level, the lack of access to transportation to avail of a service provided at a distance, and the lack of a person to take an older person to seek care can also prove to be significant barriers to access.

\section{Affordability, or the lack of it}

In most countries of the SEAR, state is the largest provider of health services, but many have poor allocations to healthcare in the national budget. Public health expenditure in India and Bangladesh stands at less than $2 \%$ of GDP. In these countries, the percentage of total health expenditure which is spent out-of-pocket is greater than $50 \%$. This points to the fact that there is a large percentage of people opting to purchase more costly private healthcare, perceiving it to be of better quality. Also, even if medical services in staterun hospitals are free, patients often need to make contributions, such as purchasing medications and drugs. Catastrophic health expenditure is a documented cause of pushing people and families into poverty, while the high burden of chronic disease in the elderly makes them particularly vulnerable to suffer such expenditure.

\section{Awareness, or the lack of it}

The levels of literacy in older populations in the SEAR range from moderate to low. Health literacy refers to the personal characteristics and social resources needed for individuals and communities to 
access, understand, appraise and use information and services to make decisions about health or have implications for health. Health literacy includes the capacity to communicate, assert and enact these decisions (14). Studies show that lack of awareness is a cause for many health problems in older people to go undetected (15). In a 2014 National Survey on Self-reported Household Health Status in Sri Lanka, $18.1 \%$ of those above 65 years of age reported having diabetes mellitus while $30.4 \%$ reported hypertension. Notably, of those not reporting diabetes, only about a third (30.1\%) had their blood glucose checked, and of those not reporting hypertension, only about a fifth (19.4\%) had their blood pressure checked (16). The knowledge of and supportive environment for delivery of healthcare and services are important determinants of the health of the older population.

\section{The 'absence' phenomenon, or deficiencies in the health human power situation}

A critical determinant of the effectiveness of any health system is the availability and quality of the human resource deployed therein. South East Asian countries face diverse health workforce challenges. While there are significant differences between the countries of the region with respect to their healthcare indices and level of development, common problems include the lack of sufficient numbers of trained workers in peripheral areas, maldistribution of the workforce in favour of urban and more developed areas, and difficulties in retaining trained workers in areas where they are needed (17). Healthcare for the older population is in general embedded within the health services of most of the countries in SEAR, with special programs for the elderly only recently making an appearance within the health system. India has launched a National Program for the Healthcare of the Elderly (NPHCE), and a 2016 paper from Sri Lanka states that a national plan is currently being finalized by the National Secretariat for Elders, the health content of which is being developed in parallel with the National Strategic Framework for Development of Health Services 20162025 (16,18). It must be seen if these programs and approaches help in the human resource situation for the elderly population.

\section{Accountability, or the lack of it}

Accountability entails the procedures and processes by which one party justifies and takes responsibility for its activities. Accountability in the health system is a relevant issue at many levels, a 1996 paper argues that parties can be held accountable for as many as six activities: professional competence, legal and ethical conduct, financial performance, adequacy of access, public health promotion and community benefit (19). In the countries of SEAR, what is the level to which the state takes responsibility for the healthcare of one of its most vulnerable segments - the elderly? This question needs to be asked from the most basic level of a provider working with elderly clients at a peripheral rural outpost, to the ministries of health allocating sufficient support monetary and otherwise - to the development of programs to support the healthcare of the elderly.

\section{The way forward - Community Physicians must play a role}

Countries of the SEAR have taken cognizance of and are developing or implementing programs and policies for the welfare of their elderly populations. Initiatives in the social sector include concessions on travel, higher interest rates in banks for senior citizens, lowered income tax slabs and limited pensions for vulnerable elders such as those with disability, those below poverty line and those who are single (widows/ widowers).

The Eastern cultures still place the role of the family and home-based caregiving at a central point in the approach to the care of the elderly, with most elderly people preferring to live in their family homes with their children or that of their relatives. Old age in itself does not indicate a need for specialist geriatric care. Hence, in their planning for the future, most countries are aiming to strengthen the community-based care system by a system of health volunteers for care of the elderly (Myanmar), establishing health and wellness centres with a domiciliary care component (India), building upon the existing healthy lifestyle centres to see if they can reach out to the community-dwelling elderly (Sri Lanka) or setting up home care projects co-ordinated by field co-ordinators and volunteers with non-governmental organizations (NGO) involvement (Indonesia) (20). Strengthening community-based initiatives and facilities for older persons, like the establishment of day care centres, social clubs and elders' committees can help in the overall wellbeing of the elderly. 
At the level of health centre, most countries have recognized the need to have medical officers and personnel trained in the principles of geriatrics. In addition, infrastructural changes making the centres more senior-accessible and senior-friendly (the WHO Age-friendly Primary Health Care Centre Toolkit has been mentioned in this connection) are also being planned (21). The availability of appliances and equipment relating to the specific needs of elders with disability and musculoskeletal disorders is also on the agenda of most countries, as they equip their health centres to become more responsive to the health needs of older persons. The way forward should include a strong health centre at primary/ secondary level, which can serve as a referral and guidance point upwards from the community, with trained and responsive personnel, drugs and medications available in sufficient quantity and basic equipment which is required for geriatric care.

The role which community physicians can play in designing and developing senior-friendly health systems at the health centre and community level is significant. As professionals trained in the scientific understanding of the specific needs of vulnerable segments of the population and in the design and implementation of programs in the health sector, the contribution of community physicians in the elderly healthcare scenario must be sought and utilized. They can play a role in the assessment-design-implementationevaluation program cycle, and their expertise in this area must be utilized.

At tertiary levels of healthcare and at district and regional levels, the accent in most countries is to develop referral centres which are equipped with trained geriatricians to serve as teaching and referral units. Other functions which the referral unit could serve include training of the primary care team, rehabilitation and long-term care.

Geriatrics as a specialty has not gained traction in most countries in the region and needs to be planned for in the higher medical education policy. In addition to geriatric medical specialists, paramedical workers need to be trained and planned for, in adequate numbers, including home-care support workers, communitylevel nurses and staff providing physiotherapy and psychiatric support.

With the numbers of people above 60 years of age in the world and in SEAR poised to rise, the challenge for the health sector is to make a meaningful health service available in some form to this growing and needy segment of the population.

\section{References}

1. Partridge L \& Mangel M. Messages from mortality: the evolution of death rates in the old. Trends in Ecology \& Evolution 1999; 14(11): 438-442.

2. WHO Technical Report series (TRS) 779. Health of the Elderly. Report of a WHO Expert Committee, 1987.

3. Rao AV. Socio-economic problems (of the elderly). In: OP Sharma (Ed.), Geriatric care in India. Delphi: A n B Publishers, 1999.

4. WHO South East Asian Regional Office. Health situation and trend assessment. The elderly population.

Available from: http://www.searo.who.int/entity/ health_situation_trends/data/chi/elderly-population/en/

5. United Nations, Department of Economic and Social Affairs, Population Division (2017). World Population Ageing 2017 - Highlights (ST/ESA/SER.A/397).

6. WHO Regional Office for South-East Asia. Regional strategy for healthy ageing: 2013-2018. Geneva: World Health Organization, 2014.

7. The World Bank. Data. Washington, DC: World Bank. Available from: https://data.worldbank.org/indicator/ SP.DYN.TFRT.IN/

8. The World Fact Book. Central Intelligence Agency, Government of the United States of America. Available from: https://www.cia.gov/library/ publications/the-world-factbook/fields/2177.html

9. The World Bank. Data. Washington, DC: World Bank. Available from: https://data.worldbank.org/indicator/ SP.DYN.LE00.IN

10. WHO. Global health observatory data repository, life expectancy and healthy life expectancy data. Geneva: WHO Region.

Available from: http://apps.who.int/gho/data/ view.main.SDG2016LEXREGv?lang=en

11. WHO Technical Report Series (548). Planning and organization of geriatric services. Report of a WHO Expert Committee, 1974.

12. Kasthuri A. Challenges to healthcare in India - The five A's. Indian Journal of Community Medicine 2018; 43: 141-143.

13. Dey S, Nambiar D, Lakshmi JK, et al. Health of the elderly in India: challenges of access and affordability. In: National Research Council (US) Panel on Policy Research and Data Needs to Meet the Challenge of Aging in Asia. Smith JP, Majmundar M (Eds.), Aging in Asia: Findings from new and emerging data 
initiatives. Washington (DC): National Academies Press (US), 2012.

Available from: https://www.ncbi.nlm.nih.gov/books/ NBK109208/

14. Dodson S, Good S, Osborne RH. Optimizing health literacy: improving health and reducing health inequities: a selection of information sheets from the health literacy toolkit for low and middle-income countries. New Delhi: World Health Organization Regional Office for South-East Asia, 2015.

15. Samaraweera D \& Maduwage S. Meeting the current and future health-care needs of Sri Lanka's ageing population. WHO South-East Asia Journal of Public Health 2016; 5: 96-101.

16. DCS. National Survey on Self-reported Health in Sri Lanka 2014. Colombo: Department of Census and Statistics, Ministry of National Policies and Economic Affairs, 2016.

17. Churnrurtai Kanchanachitra, Magnus Lindelow, Timothy Johnston, Piya Hanvoravongchai, Fely Marilyn Lorenzo, Nguyen Lan Huong, Siswanto Agus
Wilopo, Jennifer Frances dela Rosa; Human resources for health in Southeast Asia: shortages, distributional challenges, and international trade in health services. Lancet 2011; 377: 769-781.

18. The National Program for the Healthcare of the Elderly. Ministry of Health \& Family Welfare, Government of India.

Available from: https://mohfw.gov.in/about-us/ departments/departments-health-and-family-welfare/ national-programme-health-care-elderly-nphce

19. Emanuel EJ \& Emanuel LL. What is accountability in health care? Annals of Internal Medicine 1996; 124(2): 229-239.

20. Myint Han. Health care of the elderly in Myanmar. WHO SEARO Regional Health Forum 2012; 16(1): 23-28.

21. Age-friendly Primary Health Care Centres Toolkit. Geneva: World Health Organization, 2008.

Available from: http://apps.who.int/iris/bitstream/ handle/10665/43860/9789241596480_eng.pdf? sequence $=1$ 